\title{
Efeito da granulometria do resíduo sólido urbano na composição do biogás proveniente de biorreatores anaeróbicos
}

A urbanização crescente traz um aumento considerável da produção de resíduos sólidos urbanos (RSU), sendo necessária a criação de alternativas que minimizem os impactos do descarte desse material no ambiente. A disposição dos RSU em aterros sanitários representa uma das destinações ambientalmente adequadas no contexto brasileiro. Nestes locais a degradação dos resíduos ocorre por meio de um processo anaeróbio que origina uma mistura gasosa denominada biogás, o qual é composto, basicamente, por metano, dióxido de carbono e outros gases em menores concentrações. Estudos realizados em biorreatores têm por objetivo o conhecimento das condições de degradação da matéria orgânica e dos fatores que favorecem ou prejudicam este processo. Diante disso, o objetivo deste trabalho foi analisar a influência da granulometria do RSU na composição do biogás proveniente de três biorreatores anaeróbios com resíduos diferentes granulometrias (entre 4 e $8 \mathrm{~mm}$ ) instalados no município de Itanhandu/MG. Para isso foi realizado o monitoramento da composição do biogás proveniente destes biorreatores. Além disso, realizou-se a caracterização físico-química do resíduo utilizado no experimento. Os resíduos utilizados no enchimento dos biorreatore eram detentores de grande carga orgânica e ao fim do experimento demonstraram que houve degradação do material depositado. De maneira geral, a redução da granulometria se mostrou um parâmetro favorável, para as condições do estudo no aumento do percentual de metano.

\section{Effect of granulometry of municipal solid waste in composition of biogas from anaerobic bioreactors}

\begin{abstract}
The growing urbanization brings a considerable increase of municipal solid waste (MSW), requiring the creation of alternatives that minimize the impacts of the disposal of this material in the environment. The disposal of MSW in landfills represents one of the environmentally appropriate destinations in the Brazilian context. In these places, the waste degradation occurs through an anaerobic process that results to a gas mixture called biogas, which is composed basically by methane, carbon dioxide and other gases in lower concentrations. Bioreactor studies to the knowledge of the conditions of degradation of organic matter and of the factors that promote orhinder this process. Given this, the objective of this work was to analyze the influence of the granulometry of the MSW in the composition of biogas from three anaerobic bioreactors with different granulometries waste (between 4 and $8 \mathrm{~mm}$ ) installed in the municipality of Itanhandu/MG. The monitoring of the composition of biogas from these bioreactors was done. Physico-chemical characterization was made of the residue used in the experiment. Waste used in the bioreactors had of large organic load and the end of the experiment demonstrated that there has been degradation of the material deposited. In General, the reduction in particle size proved to be a parameter, to the conditions of the study increasing the percentage of methane of biogas produced.
\end{abstract}

Keywords: Anaerobic Degradation; Bioreactor; Granulometry; Biogas.

Topic: Desenvolvimento, Sustentabilidade e Meio Ambiente

Reviewed anonymously in the process of blind peer
Received: 04/02/2020

Approved: 09/03/2020
Ana Cristina de Oliveira Santos Pereira (iD Universidade Federal de Itajubá, Brasil http://lattes.cnpq.br/8794078127923852 http://orcid.org/0000-0001-5544-5830 cris.unifal@gmail.com

\section{Bárbara Karoline Flauzino}

Universidade Federal de Itajubá, Brasil http://lattes.cnpq.br/2969253359385771

barbara@ixconsult.com.br

Afonso Henriques Moreira Santos (iD Universidade Federal de Itajubá, Brasil http://lattes.cnpq.br/3728767799603880 http://orcid.org/0000-0002-4454-5112 afonsohms@gmail.com

\author{
Reinaldo Corrêa Cardoso Júnior (iD \\ Centro Universitário de Itajubá, Brasil \\ http://lattes.cnpq.br/5769209326817632 \\ http://orcid.org/0000-0002-0853-2701 \\ reinaldo.junior@ixconsult.com.br \\ Eruin Martusceli Ribeiro (iD \\ Centro Universitário de Itajubá, Brasil \\ http://lattes.cnpq.br/6784820659180642 \\ http://orcid.org/0000-0001-7935-9742 \\ eruin.ribeiro@gmail.com \\ Geraldo Lucio Tiago Filho (iD) \\ Universidade Federal de Itajubá, Brasil \\ http://lattes.cnpq.br/1838249887289555 \\ http://orcid.org/0000-0002-1665-0900 \\ tiago@unifei.edu.br
}

\section{Referencing this:}

PEREIRA, A. C. O.; FLAUZINO, B. K.; SANTOS, A. H. M.; CARDOSO JÚNIOR, R. C.; RIBEIRO, E. M.; TIAGO FILHO, G. L.. Efeito da granulometria do resíduo sólido urbano na composição do biogás proveniente de biorreatores anaeróbicos. Revista Ibero Americana de Ciências Ambientais, v.11, n.2, p.350-359, 2020. DOI: http://doi.org/10.6008/CBPC2179-6858.2020.002.0032 


\section{INTRODUÇÃO}

A urbanização crescente traz um aumento considerável da produção de resíduos sólidos urbanos (RSU), só em 2016 foram gerados no país cerca de 59 milhões de toneladas de RSU (BRASIL, 2018), sendo necessária a criação de alternativas que minimizem os impactos do descarte desse material no ambiente. De acordo com Silva (2012), a destinação final ambientalmente adequada dos RSU, no contexto brasileiro, é a disposição em aterros sanitários, que em 2016 receberam 59\% dos RSU gerados no país (BRASIL, 2018). Nesses locais, a degradação dos resíduos ocorre por meio de um processo anaeróbio, ou seja, na ausência de oxigênio, originando uma mistura gasosa denominado biogás (GÜLZOW, 2010). Segundo Boscov (2008), o biogás é formado, basicamente, por $60 \%$ de metano, $35 \%$ de dióxido de carbono e $5 \%$ de uma mistura de outros gases, tais como hidrogênio, nitrogênio, gás sulfídrico, monóxido de carbono, amônia, oxigênio e aminas voláteis.

O biogás gerado nos aterros sanitários pode ser aproveitado de diversas maneiras, para geração de energia elétrica com motores de combustão interna ou microturbinas, para uso veicular, iluminação, dentre outros. $O$ interesse na geração de energia elétrica a partir do biogás de aterros tem aumentado no Brasil nos últimos anos. Em 2002, havia somente uma usina térmica movida a biogás em operação no país, saltando para 20 em 2018, que totalizam cerca de 140 MW de potência instalada (ANEEL, 2019).

Estudos envolvendo aterros em escala real apresentam custo elevado, devido ao grande número de variáveis envolvidas no processo, que dificultam e encarecem a obtenção de dados sob condições controladas (SOUSA et al., 2012). Uma das maneiras para desenvolver estudos envolvendo a produção de biogás é a utilização do biorreator, que permite a compreensão do processo de decomposição anaeróbia, pois propicia condições ideais para o desenvolvimento de microrganismos responsáveis pela degradação da matéria orgânica e produção de biogás.

Estudos desenvolvidos em biorreatores têm por finalidade o conhecimento das condições de degradação da matéria orgânica, possibilitando a verificação e alteração das condições ambientais e operacionais que favorecem a decomposição anaeróbia, possibilitando a melhora na eficiência da produção de biogás (SLEZAK et al., 2015). Conforme Barros (2013), os parâmetros passíveis de intervir no processo de digestão anaeróbia de RSU são pH, presença de inoculo, fração orgânica dos resíduos, proporção C:N, temperatura, dimensão da partícula e grau de compactação do RSU.

A composição dos resíduos sólidos urbanos é extremamente heterogênea, podendo variar muito em tamanhos de partículas (LIMA, 2004). A granulometria é uma propriedade física dos RSU considerada interveniente nos sistemas anaeróbios, uma vez que pode limitar principalmente, a fase de hidrólise e reduzir a eficiência do sistema de tratamento (LEVINE et al., 1991). Assim, o conhecimento sobre a distribuição de tamanho das partículas possibilita o delineamento dos mecanismos de remoção de matéria orgânica sendo fundamental para o aperfeiçoamento das alternativas tecnológicas de tratamento biológico. A redução do tamanho das partículas por trituração em veículos de coleta ou em estações de transferência aumenta significantemente a reatividade do processo, devido ao aumento da área superficial de contato do substrato 
disponível ao ataque enzimático dos microrganismos. Nesse contexto, o objetivo desse trabalho foi avaliar a produção e composição do biogás proveniente de biorreatores com resíduos de diferentes granulometrias.

\section{METODOLOGIA}

O estudo foi conduzido no município de Itanhandu ( $22^{\circ} 17^{\prime} 12^{\prime \prime} \mathrm{S}$ e $44^{\circ} 56^{\prime} 71^{\prime \prime} \mathrm{O}$ região Sul do Estado de Minas Gerais. De acordo com o IBGE (2019), em 2018 o município possuía população estimada em 15.236 habitantes em uma área territorial de cerca de $154 \mathrm{~km}^{2}$, resultando em uma densidade demográfica de cerca de $99 \mathrm{hab} / \mathrm{km}^{2}$. Segundo a classificação de Köppen-Geiger (1928), o clima é Cwa, com maior pluviosidade no verão do que no inverno. A temperatura média anual é de 19 o $\mathrm{C}$ e pluviosidade média anual de $1.490 \mathrm{~mm}$.

No experimento foram utilizados três biorreatores, a fim de estudar a interferência da granulometria do resíduo sobre a composição do biogás (concentrações de $\mathrm{CH}_{4}, \mathrm{CO}_{2}$ e $\mathrm{O}_{2}$ ), proveniente da degradação anaeróbia dos resíduos neles dispostos.

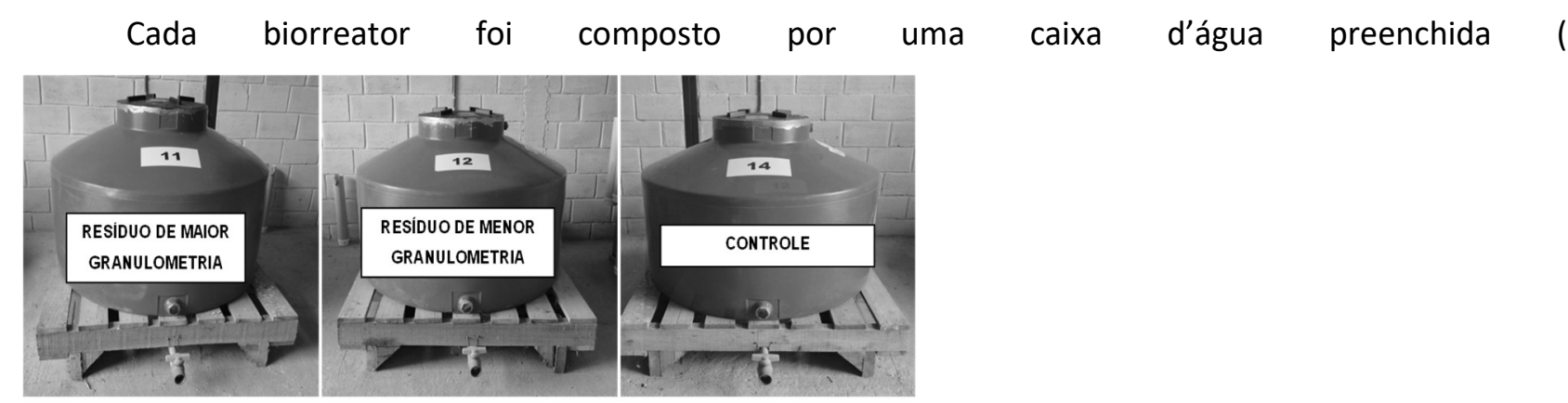

Figura 1), sobretudo, com a fração orgânica do RSU. Em cada um deles foram instalados drenos para a coleta de biogás e chorume. Um dos biorreatores foi preenchido com resíduo de pequena granulometria ( $4 \mathrm{~mm})$, outro com resíduo de maior granulometria $(\sim 8 \mathrm{~mm})$, e o terceiro, foi preenchido com uma mistura proporcional de resíduos de maior e menor granulometrias $(\sim 6 \mathrm{~mm})$, utilizado como controle.

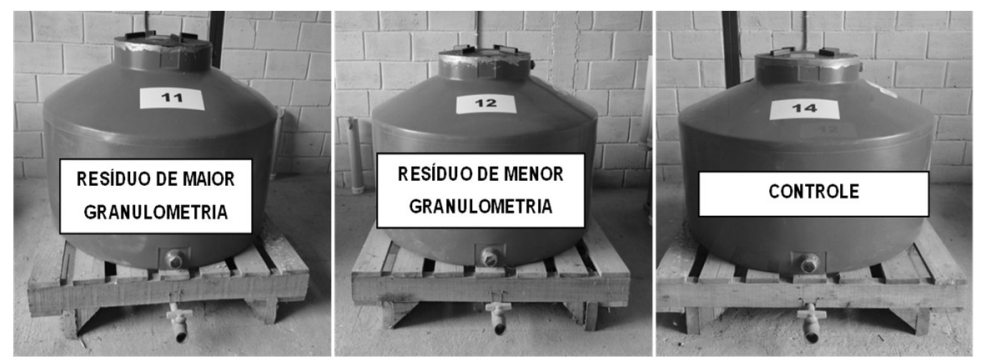

Figura 1: Comparação da porcentagem de material retido com o tamanho da malha, em mm, em cada peneira.

Os resíduos utilizados para o enchimento dos biorreatores foram picados em uma picadeira do tipo ensiladeira acionada pelo motor de trator. Para obter a granulometria desejada, o procedimento adotado foi o de associação de polias grandes e pequenas na picadeira. A fim de constatar a diferença de tamanho entre os resíduos, foi realizada a determinação da composição granulométrica, por meio de análise granulométrica baseada em uma adaptação da determinação de agregados do solo (EMBRAPA, 1997).

As amostras foram secadas, pesadas e passadas por uma série de cinco peneiras, com aberturas de $30 \mathrm{~mm}, 10 \mathrm{~mm}, 8 \mathrm{~mm}, 4 \mathrm{~mm}$ e $2 \mathrm{~mm}$. No procedimento de determinação da granulometria foi observado que as peneiras de $30 \mathrm{~mm}$ e $10 \mathrm{~mm}$ retiveram apenas materiais não orgânicos, os quais foram descartados. De 
do

ensaio

de

granulometria

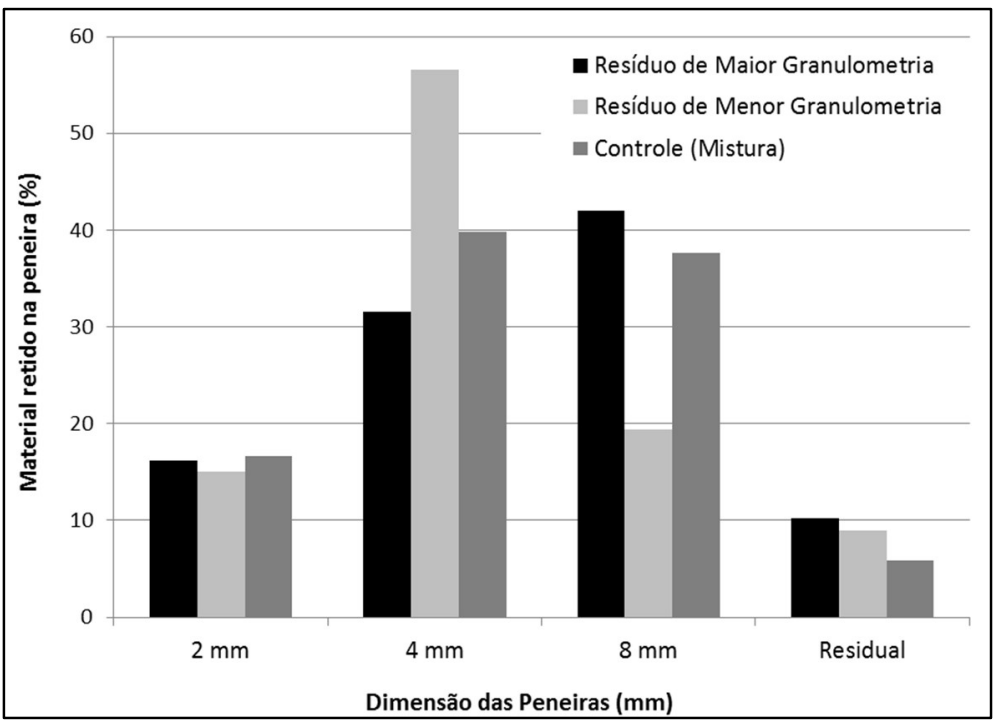

Figura 2), $15 \%$ do resíduo de menor granulometria ficou retido na peneira de $2 \mathrm{~mm}$, cerca de $60 \%$ na peneira de $4 \mathrm{~mm}$ e aproximadamente $20 \%$ na peneira de $8 \mathrm{~mm}$.

Para o resíduo de maior granulometria, em torno de $40 \%$ do material foi retido na peneira de $8 \mathrm{~mm}$, $30 \%$ na peneira de $4 \mathrm{~mm}$ e 16\% na peneira de $2 \mathrm{~mm}$. Já para o biorreator controle, cuja composição foi a mistura de resíduos, aproximadamente 35\% ficaram retidos na peneira de $8 \mathrm{~mm}, 43 \%$ na de $4 \mathrm{~mm}$ e $16 \%$ na peneira de $2 \mathrm{~mm}$. Portanto, a determinação da granulometria indicou a existência de diferença entre as granulometrias dos resíduos utilizados no enchimento dos biorreatores.

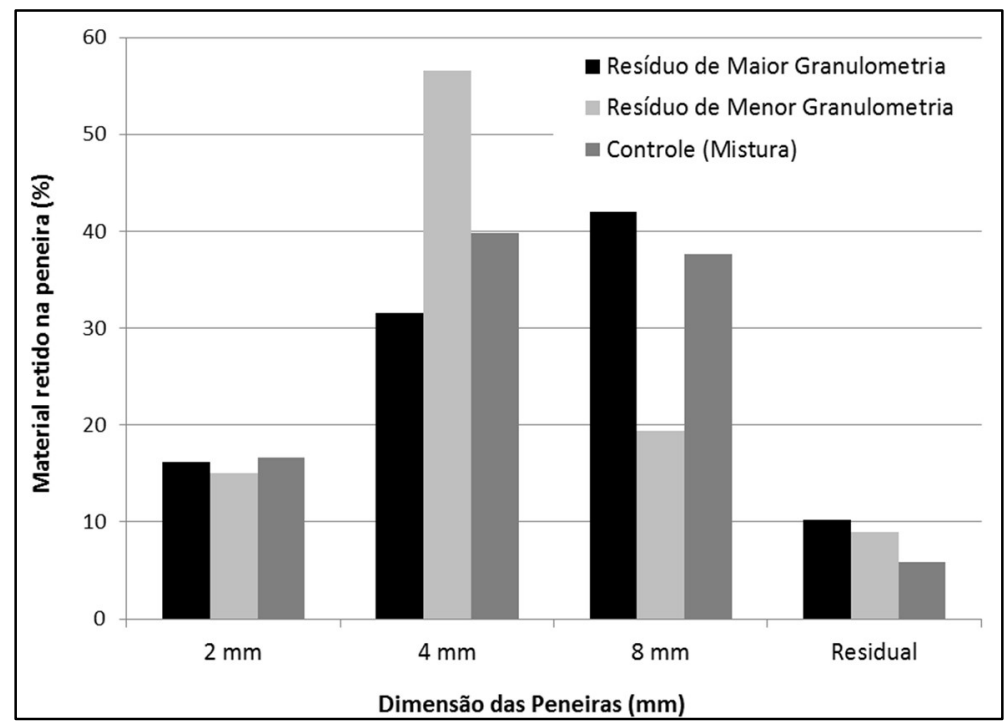

Figura 2: Comparação da porcentagem de material retido com o tamanho da malha, em mm, em cada peneira.

Posteriormente à determinação da granulometria dos resíduos, em cada biorreator foi coletada uma amostra, com cerca de $2 \mathrm{~kg}$, dos resíduos depositados para a caracterização do material utilizado. As amostras foram encaminhadas para o Laboratório de Resíduos Sólidos, Hidrogeologia e Qualidade da Água (LABRES) da Universidade Federal de Itajubá (UNIFEI), para determinação de onze parâmetros físicoquímicos: pH, sólidos totais, fixos e voláteis, alcalinidade, demanda química de oxigênio, demanda bioquímica de oxigênio, nitrogênio total, carbono orgânico total, umidade e matéria seca, de acordo com as 
metodologias preconizadas no Standard Methods for the Examination of Water and Wastewater (APHA, 1998).

Na sequência, foi realizado o enchimento dos biorreatores. Para a obtenção da massa do material picado foi utilizada uma balança eletrônica de bancada com capacidade de $60 \mathrm{Kg}$. Os resíduos orgânicos picados foram dispostos em um tambor plástico, encaminhados para a pesagem e em seguida colocados no biorreator.

Na Tabela 1 é possível verificar os dados sobre o tamanho do resíduo, data e quantidade de resíduos utilizados no enchimento de cada um dos biorreatores. Um dos biorreatores foi preenchido apenas com resíduo de pequena granulometria, outro com resíduo de maior granulometria, e o terceiro foi preenchido com uma mistura proporcional de resíduos de maior e menor granulometrias, utilizado como controle.

Tabela 1: Tamanho do resíduo, data e quantidade de resíduos utilizados no enchimento dos biorreatores.

\begin{tabular}{|c|c|c|c|}
\hline Biorreator & $\begin{array}{l}\begin{array}{l}\text { Tamanho Médio do } \\
\text { Resíduo }\end{array} \\
\end{array}$ & Data de Enchimento & $\begin{array}{l}\text { Quantidade de } \\
\text { Resíduo }\end{array}$ \\
\hline Biorreator com resíduo de maior granulometria & $8 \mathrm{~mm}$ & $29 / 05 / 15$ & $490,0 \mathrm{~kg}$ \\
\hline $\begin{array}{l}\begin{array}{l}\text { Biorreator com resíduo de } \\
\text { granulometria }\end{array} \\
\end{array}$ & $4 \mathrm{~mm}$ & $29 / 05 / 15$ & $498,6 \mathrm{~kg}$ \\
\hline Controle & $\geq 4 \mathrm{~mm} \mathrm{e} \leq 8 \mathrm{~mm}$ & $28 / 04 / 15$ & $490,3 \mathrm{~kg}$ \\
\hline
\end{tabular}

Após o enchimento dos biorreatores e estabilização do processo de degradação, foi feito o monitoramento do biogás produzido nos biorreatores por meio do analisador de gás GEM 5000 Landtec ${ }^{\circ}$,

conforme mostrado na
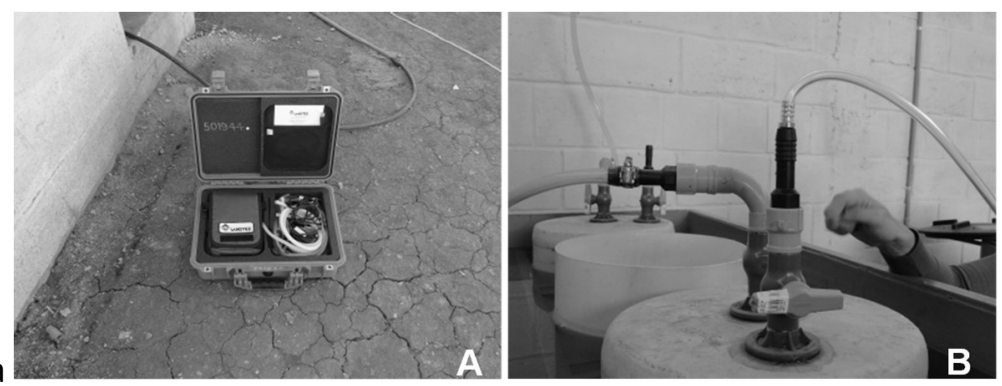

Figura 3. A composição do biogás foi dada pela porcentagem presente de metano $\left(\mathrm{CH}_{4}\right)$, dióxido de carbono $\left(\mathrm{CO}_{2}\right)$ e oxigênio $\left(\mathrm{O}_{2}\right)$.
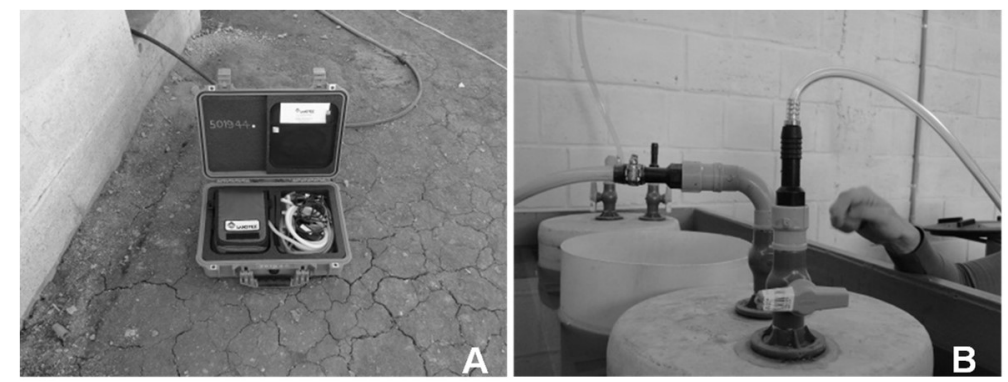

Figura 3: Monitoramento do volume, pressão e composição do biogás produzido nos biorreatores. (A) Analisador de gás GEM 5000 Landtec $^{\circledR}$ (B) Gasômetros

O monitoramento da composição dos biorreatores foi realizado no período de 01/10/2015 a 30/09/2016, totalizando 365 dias, ou seja, um ano de aquisição de dados.

\section{RESULTADOS}




\section{Caracterização dos resíduos}

Os parâmetros físico-químicos analisados nos resíduos utilizados no enchimento dos biorreatores foram $\mathrm{pH}$, sólidos totais, fixos e voláteis, alcalinidade, demanda química de oxigênio, demanda bioquímica de oxigênio, nitrogênio total, carbono orgânico total, umidade e matéria seca. Os valores encontrados para os parâmetros físico-químicos estão na Tabela 2.

Tabela 2: Parâmetros físico-químicos dos resíduos utilizados no enchimento dos biorreatores.

\begin{tabular}{|l|l|l|l|}
\hline Parâmetro físico-químico & Biorreator Resíduo Grande & Biorreator Resíduo Pequeno & Biorreator Mistura \\
\hline $\mathrm{pH}$ & 7,19 & 7,75 & 6,08 \\
\hline Sólidos totais (mg/L) & 4.982 & 2.340 & 3.153 \\
\hline Sólidos totais fixos (\%) & 47,4 & 39,9 & 32,0 \\
\hline Sólidos totais voláteis (\%) & 52,6 & 60,1 & 68,0 \\
\hline Alcalinidade (mg/L) & 280 & 240 & 337 \\
\hline Demanda química de oxigênio (mg/L) & 1.190 & 1.056 & 1.024 \\
\hline Demanda bioquímica de oxigênio (mg/L) & 755,4 & 632,5 & 515,9 \\
\hline Nitrogênio total (mg/L) & 31,15 & 7,35 & 29,12 \\
\hline Carbono orgânico total (mg/L) & 850,4 & 862,8 & 1292 \\
\hline Umidade (\%) & $60 \%$ & $60 \%$ & $56 \%$ \\
\hline Material Seco (\%) & $40 \%$ & $40 \%$ & $44 \%$ \\
\hline
\end{tabular}

\section{Monitoramento da produção do Biogás}

Os resultados obtidos a partir do monitoramento da composição do biogás do Biorreator Controle estão na Figura 4. A composição do biogás observada durante o período de monitoramento no biorreator com resíduo de menor granulometria está na

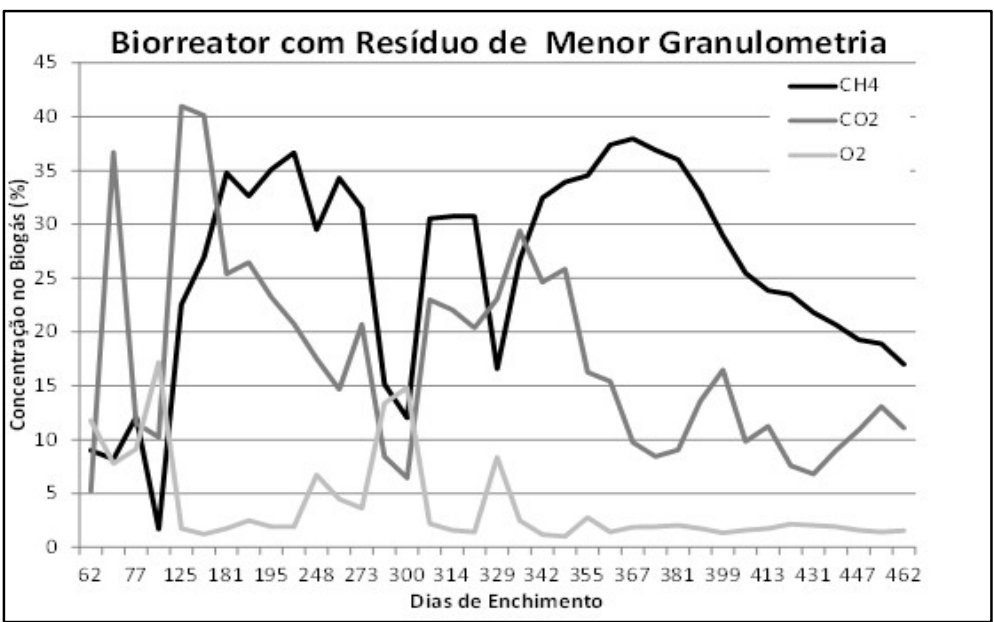

Figura 5. Na Figura 6 estão os resultados obtidos para a composição do biogás do biorreator com resíduo de maior granulometria. 


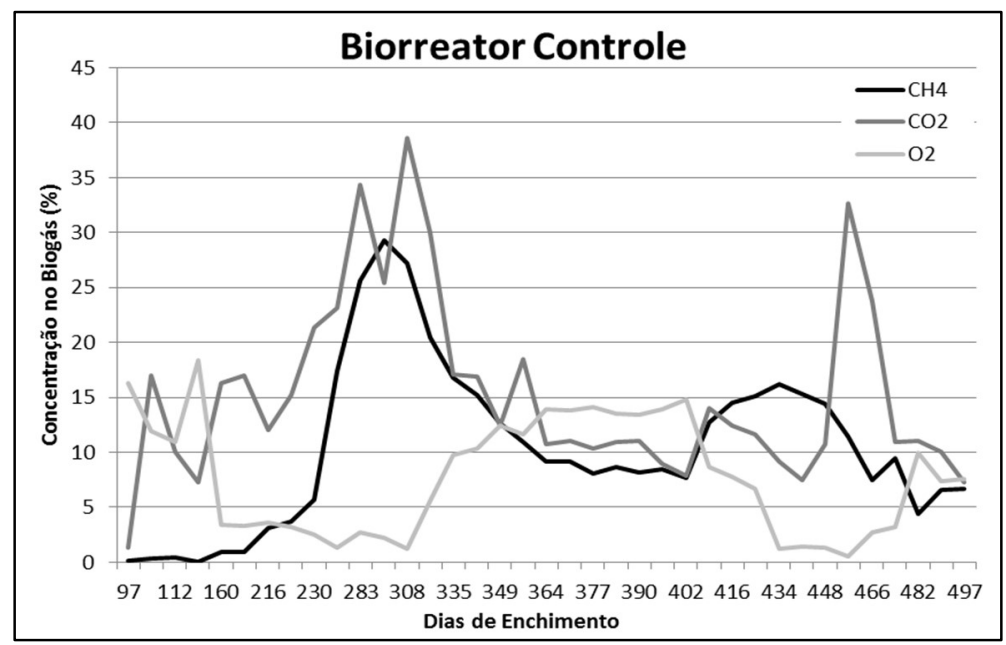

Figura 4: Monitoramento do biogás no biorreator controle referente ao período de 01/10/2015 a 30/09/2016.

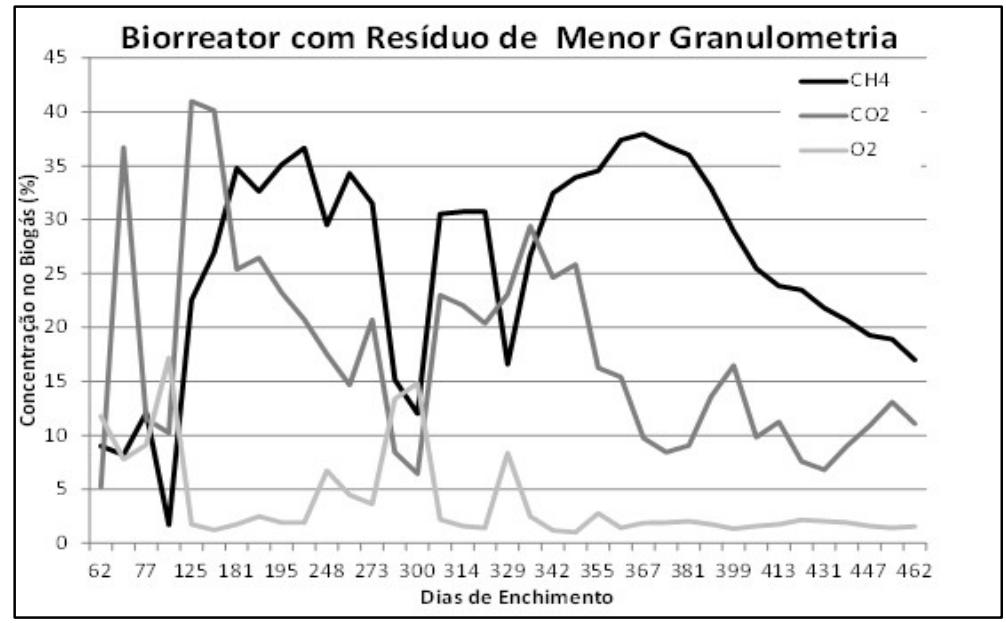

Figura 5: Monitoramento do biogás no biorreator com resíduo de menor granulometria referente ao período de 01/10/2015 a 30/09/2016.

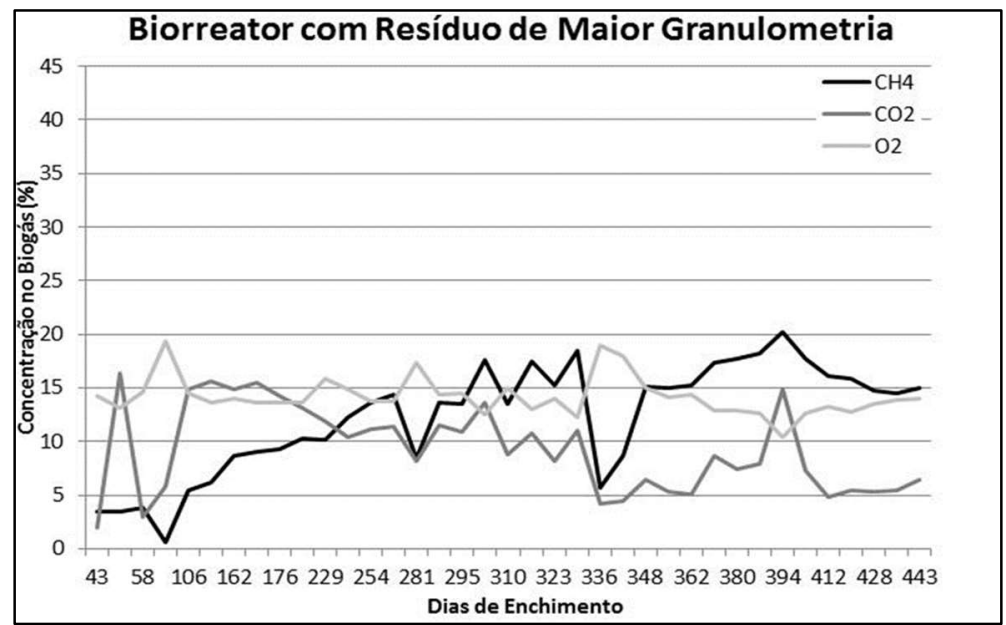

Figura 6: Monitoramento do biogás no biorreator com resíduo de maior granulometria referente ao período de 01/10/2015 a 30/09/2016.

\section{DISCUSSÃO}

\section{Caracterização dos resíduos}

De acordo com Barcelos (2009), a análise química dos resíduos identifica a composição do substrato, possibilitando a avaliação do grau de resistência à atividade enzimática e da disponibilidade de nutrientes para os microrganismos. De maneira geral, os parâmetros físico-químicos analisados nos resíduos utilizados 
no enchimento dos biorreatores indicaram a presença de significativa fração orgânica, e consequentemente grande potencial de biodegradabilidade.

Segundo a Tabela 2, os valores de pH variaram de 6,08 a 7,75 e, segundo Monteiro et al. (2001), valores de $\mathrm{pH}$ próximos à faixa de 4 a 7 revelam a presença de matéria orgânica fresca e livre da decomposição avançada. Os percentuais de sólidos totais voláteis estiveram entre 52,6 e $68 \%$ que, conforme Leite (2008), concentrações de sólidos voláteis superiores a 60\% indicam a presença significativa de material passível de degradação.

A biodegradabilidade dos resíduos pode ser indicada por meio da análise conjunta da DQO e DBO. Segundo Von Sperling (2005), materiais com valores de DQO/DBO de até 2,5 possuem uma fração biodegradável elevada, fato observado para os resíduos utilizados no experimento, que apresentaram valores de até 1,98. A concentração de carbono orgânico total esteve entre 850,4 e $1292 \mathrm{mg} / \mathrm{L}$, enquanto que a de nitrogênio foi de 7,35 a até $31,15 \mathrm{mg} / \mathrm{L}$. A proporção $\mathrm{C} / \mathrm{N}$ é um parâmetro relevante e, segundo Barros (2013), proporções inadequadas de C/N podem prejudicar a digestão anaeróbia dos resíduos. Nesse estudo os valores da proporção C/N variaram de 27,30 a 117,38.

Quanto à umidade, a manutenção da quantidade ideal de água é essencial para as reações bioquímicas, oferta de nutrientes e ajustamento do pH (LIBÂNIO et al., 2003). A umidade ideal para a degradação dos resíduos está situada na faixa de 40-60\% (BIDONE et al., 1999), sendo que os resíduos utilizados no enchimento dos biorreatores possuíam umidade nessa faixa. Fei et al. (2016) demonstraram que fatores como umidade, nutrientes e temperatura são os fatores de maior impacto nas condições de biodegradação de resíduos, pois favorecem o aumento do potencial de geração de metano e diminuem o tempo de degradação.

De acordo com Metcalf et al. (1991), citado por Barcelos (2009), a alcalinidade deve ser capaz de manter o pH na região 6,6 e 7,6, e a faixa ideal de alcalinidade para o bom funcionamento do processo anaeróbio é de 1.000 e $5.000 \mathrm{mg} / \mathrm{L}$. Os resíduos de todos os biorreatores apresentaram valores de alcalinidade abaixo da faixa ideal, sugerindo que a neutralização dos ácidos pode não ser efetiva, o que pode prejudicar o processo de degradação anaeróbia.

\section{Monitoramento da produção do Biogás}

O monitoramento dos gases gerados pela biodegradação auxilia na análise da evolução do processo de decomposição da matéria orgânica (ALCÂNTARA, 2007). De acordo com Tchobanoglous et al. (1993), o biogás proveniente da degradação anaeróbia de resíduos é composto, principalmente, por metano (35 a $60 \%$ ) e gás carbônico (40 a 60\%).

No biorreator controle (Figura 4) a produção de metano foi observada desde o início do monitoramento com, aproximadamente, 97 dias de enchimento, sendo que a sua concentração máxima foi de $30 \%$, inferior à preconizada na literatura. O comportamento do dióxido de carbono foi de aumento no início e diminuição no restante do período de monitoramento, atingindo valor máximo de $38 \%$. As concentrações de $\mathrm{CO}_{2}$ ao longo do estudo estiveram de acordo com o esperado. Este gás é o principal produto 
das reações iniciais de degradação anaeróbia, transformando-se em substrato para a metanogênese. Assim, passa a ser consumido, o que justifica sua redução simultaneamente ao aumento da concentração de metano.

As reações de degradação dependem das baixas concentrações de $\mathrm{O}_{2}$, pois a porcentagem de metano aumenta à medida que o $\mathrm{O}_{2}$ diminui. As concentrações de oxigênio no biorreator controle ficaram abaixo de 15\%. O processo de digestão anaeróbia demanda um ambiente praticamente ausente desse gás, e caso haja aumento da sua concentração, a reação é prejudicada. Este comportamento foi observado para o biorreator uma vez que os períodos em que o biogás apresentou maiores concentrações de $\mathrm{CH}_{4}, 0 \mathrm{O}_{2}$ estava com baixa concentração e vice-versa.

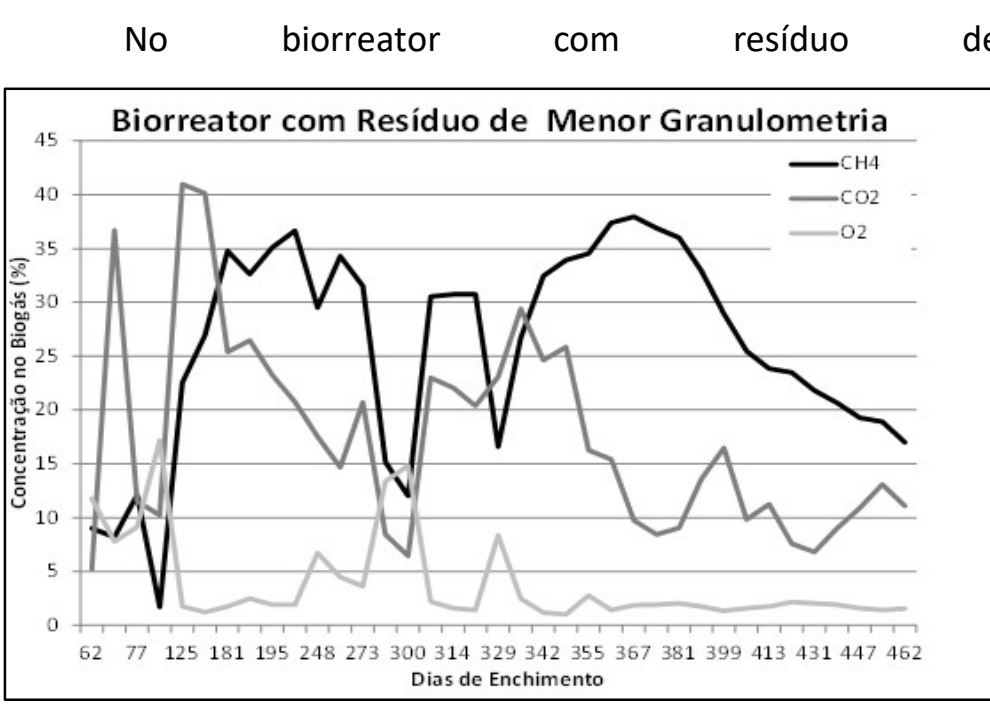

Figura 5) , foi observada a presença de metano no biogás desde o início do monitoramento, aos 62 dias de enchimento. A pequena disponibilidade de oxigênio (abaixo de 5\%) favoreceu a degradação anaeróbia e consequentemente a síntese do metano, pois neste biorreator foi observada a maior porcentagem de metano. Apesar das porcentagens de metano chegar a atingir 37\%, esses valores estão abaixo do intervalo sugerido pela literatura (TCHOBANOGLOUS et al., 1993). O comportamento do dióxido de carbono, por sua vez, foi semelhante ao do biorreator controle, apresentando aumento no início e redução no restante do período de monitoramento, o que indica seu consumo no processo de produção do metano.

Em relação à composição do biogás no biorreator com o resíduo de maior granulometria (Figura 6), a fração de metano $\left(\mathrm{CH}_{4}\right)$ no biogás atingiu valor máximo de $18 \%$, enquanto que o oxigênio $\left(\mathrm{O}_{2}\right)$ esteve com frações constantes próximas a 15\% em grande parte do monitoramento. Os resultados não satisfatórios para esse biorreator podem estar associados à presença de quantidades consideráveis de $\mathrm{O}_{2}$ no seu interior, devido aos espaços vazios existentes entre os resíduos depositados ou à entrada não planejada de ar no experimento, pois a presença de $\mathrm{O}_{2}$ interfere negativamente na degradação anaeróbia, que ocorre na ausência de oxigênio, e consequentemente afeta as concentrações de $\mathrm{CH}_{4}$ e $\mathrm{CO}_{2}$.

De maneira geral, na composição do biogás do biorreator com resíduos de maior e menor granulometrias, percebeu-se que as porcentagens de metano foram superiores ao de $\mathrm{CO}_{2}$ na segunda metade do período de monitoramento. Este comportamento difere-se do proposto por Bidone et al. (1999) 
que apontam em experimentos realizados em lisímetros, que o tamanho das partículas influenciou a composição do biogás gerado, ou seja, quando o tamanho das partículas foi reduzido de 250 para $25 \mathrm{~mm}$, a geração de gás aumentou cerca de 4,4 vezes, entretanto a composição do biogás demonstrou predominância de $\mathrm{CO}_{2}$ e não de $\mathrm{CH}_{4}$ que é o gás de interesse.

As porcentagens de metano registradas nesse trabalho, cujos valores máximos atingiram $36 \%$, estão próximas ao limite inferior dos valores reportados na literatura, que indicam concentração de metano produzido pela biodegradação anaeróbia da matéria orgânica, entre 35 a 60\%. As principais limitações para a produção do metano podem estar relacionadas à rápida acidificação devido à grande carga orgânica biodegradável do resíduo e à alta relação C/N (BOUALLAGUI et al., 2004). A diminuição do pH no interior do biorreator deveria ser neutralizada pela capacidade de tamponamento do resíduo, indicado pela alcalinidade. Nesse caso, as alcalinidades destes biorreatores foram inferiores a faixa ideal, sugerindo que a neutralização dos ácidos não ocorreu de forma efetiva.

Apesar das concentrações de metano estarem abaixo da ideal, observou-se que o biogás com a maior porcentagem de metano (36\%) foi gerado no biorreator com resíduo com menor granulometria e, de forma contrária, o biorreator com resíduo de maior dimensão gerou biogás com menores porcentagens de metano (18\%). A diminuição da granulometria de $8 \mathrm{~mm}$ para $4 \mathrm{~mm}$, duplicou a fração de metano no biogás nestes biorreatores.

Resultados semelhantes foram observados por alguns autores que utilizou materiais com diferentes tamanhos e promoveu aumento de $25 \%$ na produção de metano quando o diâmetro das partículas foi reduzido de $215 \mathrm{~mm}$ para $41 \mathrm{~mm}$. A redução granulométrica de resíduos orgânicos favoreceu a produção de biogás, fato que pode ser atribuído ao aumento da área de superfície de contato disponível do substrato, onde os microrganismos se aderem, aumentando assim a degradação do material orgânico (SANDERS et al., 2001).

Esposito et al. (2011) observaram que o aumento da granulometria da fração orgânica do RSU implica em menor taxa de produção de metano. Observou-se, então, a interferência do tamanho da partícula na quantidade de metano produzido nos biorreatores estudados, ou seja, a redução da granulometria do resíduo acarretou no aumento da quantidade de metano no biogás produzido.

Neste estudo, a redução do tamanho das partículas colaborou positivamente no processo de digestão anaeróbia dos resíduos e consequentemente na composição do biogás gerado. Resultados semelhantes foram encontrados por Warith (2002) em estudo experimental realizado para determinar o efeito da granulometria de resíduos sólidos na taxa de biodegradação de resíduos sólidos urbanos. $\mathrm{O}$ autor concluiu, experimentalmente, que a fragmentação dos RSU é um método eficaz para melhorar a biodegradação dos resíduos, em comparação com as tendências estabelecidas com os resíduos sólidos não triturados. Mshandete et al. (2006) apontaram que a quantidade de biogás pode ser significativamente aumentada através da redução granulométrica do substrato assim como a produção de metano. Os autores constataram que sua produção foi inversamente proporcional ao tamanho da partícula. 


\section{CONCLUSÕES}

A análise dos parâmetros físico-químicos indicou que a fração orgânica dos RSU utilizada no enchimento dos biorreatores apresentava, inicialmente, grande potencial de biodegradabilidade. A presença de metano no biogás produzido nos três biorreatores evidenciou a ocorrência da degradação anaeróbia dos resíduos.

De modo comparativo, o biorreator com resíduo de menor granulometria produziu biogás com a maior porcentagem de metano, o que pode estar associado à facilidade de degradação de partículas menores em comparação com partículas maiores. Foram observadas relações inversas entre as concentrações de metano e oxigênio. Sendo assim, para as condições do estudo, a redução do tamanho das partículas colaborou positivamente no processo de digestão anaeróbia dos resíduos e consequentemente na composição do biogás gerado.

\section{REFERÊNCIAS}

ANEEL. Agência Nacional de Energia Elétrica. Banco de Informações de Geração (BIG). ANEEL, 2019.

ALCÂNTARA, P. B.. Avaliação da influência da composição de resíduos sólidos urbanos no comportamento de aterros simulados. Tese (Doutorado em Engenharia Civil) Universidade Federal de Pernambuco, Recife, 2007.

APHA. American Public Health Association. Standard Methods for the Examination of Water and Wastewaters. APHA, 1998.

BARCELOS, B. R.. Avaliação de diferentes inoculos na digestão anaeróbia da fração orgânica de resíduos sólidos orgânicos. Dissertação (Mestrado em Tecnologia Ambiental e Recursos Hídricos) - Universidade de Brasília, Brasília, 2009.

BARROS, R. M.. Tratado sobre resíduos sólidos: gestão, uso e sustentabilidade. Rio de Janeiro: Interciência; Minas Gerais: Acta, 2013.

BIDONE, F. R. A.; POVINELLI, J.. Conceitos básicos de resíduos sólidos. São Carlos: EESC/USP, 1999.

BOSCOV, M. E. G.. Geotecnia ambiental. Brasília: Oficina de Textos, 2008.

BOUALLAGUI, H.; HAOUARI, O.; TOUHAMI, Y.; BEN-CHEIKH, R.; MAROUANI, L.; HANDI, M.. Effect of temperature on the performance of an anaerobic tubular reactor traiting fruit a vegetable waste, Process Biochemistry, Tunisia, v.39, n.12, p.2143-2148, 2004

BRASIL. Sistema Nacional de Informações Sobre Saneamento. Diagnósticos do Manejo de Resíduos Sólidos Urbanos: 2016. Brasília: SNIS, 2018.

EMBRAPA. Empresa Brasileira de Pesquisa Agropecuária. Manual de métodos de análise de solo. 2 ed. Rio de Janeiro: Centro Nacional de Pesquisa de Solos, 1997.

ESPOSITO, G.; FRUNZO, L.; PIROZZI, F.. Modelling the Effect of the OLR and OFMSW Particle Size on the Performances of an Anaerobic Co-digestion Reactor. Process. Biochemistry. v.46, n. 2, p.557-567, 2011.
FEI, X.; ZEKKOS, D.; RASKIN, L.. Quantification of parameters influencing methane generation due to biodegradation of municipal solid waste in landfills and laboratory experiments. Waste Management, v.55, p.276-287, 2016.

GÜLZOW, P.. Guia Prático do Biogás Geração e Utilização. 5 ed. Berlim: Fachagentur Nachwachsende Rohstoffe, 2010.

IBGE. Instituto Brasileiro de Geografia e Estatística. Cidades. Rio de Janeiro: IBGE, 2019.

LEITE, H. E. A. S.. Estudo do comportamento de aterros de RSU em um biorreator em escala experimental na cidade de Campina Grande/PB. Dissertação (Mestrado em Engenharia Civil e Ambiental) - Universidade Federal de Campina Grande, Campina Grande, 2008.

LEVINE, A. D.; TCHOBANOGLOUS, G.; ASANO, T.. Size distribution of particulate dontaminants in wastewater and their impact on treatability. Water Resource, Ames, v.25, n.8, p.911-922, 1991.

LIBÂNIO, P. A. C.; COSTA, B. M. P.; CINTRA, I. S.; CHERNICARO, C. A. L.. Evaluation of the start-up of na integrated municipal solid waste and leachate treatment system. Water Science and Technology, v.48, n.6, p.241247, 2003.

LIMA, L. M. Q.. Lixo: Tratamento e Biorremediação. 3 ed. Campinas: Hemus, 2004.

MONTEIRO, J. H. P.; FIGUEIREDO, C. E. M.; MAGALHÃES, A. F.; MELO, M. A. F.; BRITO, J. C. X.; ALMEIDA, T. P. F.; MANSUR, G. L.. Manual de Gerenciamento Integrado de Resíduos Sólidos. Rio de Janeiro: IBAM, 2001.

MSHANDETE, A.; BJORNSSON, L.; KIVAISI, A. K.; RUBINDAMAYUGI, M. S. T.; MATTIASSON, B.. Effect of Particle Size on Biogas Yield Sisal Fibre Waste. Renewable Energy, v.31, n.14, p.2385-2392, 2006.

SANDERS, W. T.; GEERING, M.; ZEEMAN, G.; LETTINGA, G. Anaerobic Hydrolysis Kinetics of Particulate Substrates. Water Science \& Technology, v.41, n.3, p.17-24, 2001.

SILVA, G. A.. Estimativa da geração de biogás no aterro sanitário metropolitano de João Pessoa através do teste BMP. Dissertação (Mestrado em Engenharia Urbana e 
Ambiental) - Universidade Federal da Paraíba, João Pessoa, 2012.

SLEZAK, S.; KRZYSTEK, L.; LEDAKOWICZ, S.. Degradation of municipal solid waste in simulated landfill bioreactors under aerobic conditions. Waste Management, v.43, p.293-299, 2015.

SOUSA, R. B. A.; AIRES, K. O.; DANTAS, E. R. B.; BATISTA, P. I. B.; MONTEIRO, V. E. D.. Análise da composição de gases em uma célula experimental de resíduos sólidos urbanos e sua relação com o pH do meio. In: SEMINÁRIO REGIONAL
NORDESTE DE RESÍDUOS SÓLIDOS, 4. Anais. São Cristóvão: UFS, 2012.

TCHOBANOGLOUS, G.; THEISEN, H.; VIGIL, S.. Integrated Solid Waste Management Engineering Principles and Management Issues. New York: McGrall-Hill Inc., 1993.

VON SPERLING, M.. Introdução à qualidade das águas e ao tratamento de esgotos. Belo Horizonte: UFMG, 2005.

WARITH, M.. Bioreactor landfills: experimental and fields results. Waste Management, v.22, p.7-17, 2002.

A CBPC - Companhia Brasileira de Produção Científica (CNPJ: 11.221.422/0001-03) detém os direitos materiais desta publicação. Os direitos referem-se à publicação do trabalho em qualquer parte do mundo, incluindo os direitos às renovações, expansões e disseminações da contribuição, bem como outros direitos subsidiários. Todos os trabalhos publicados eletronicamente poderão posteriormente ser publicados em coletâneas impressas sob coordenação da Sustenere Publishing, da Companhia Brasileira de Produção Científica e seus parceiros autorizados. Os (as) autores (as) preservam os direitos autorais, mas não têm permissão para a publicação da contribuição em outro meio, impresso ou digital, em português ou em tradução. 